\title{
Interdisciplinaridade e contextualização nos projetos políticos pedagógicos em cursos de formação inicial de professores de química
}

Francisco Marcôncio Targino de Moura

marconcio@gmail.com

000-0002-0800-9347

Universidade Federal do Ceará, Fortaleza, Ceará, Brasil.

Claudia Christina Bravo e Sá

Carneiro

ccbcarneiro@hotmail.com

Universidade Federal do Ceará, Fortaleza,

Ceará, Brasil.

\section{RESUMO}

Contextualizar o conhecimento de forma interdisciplinar passou a ser uma questão de ordem no ensino de química para o ensino médio, um requisito a ser contemplado na formação do professor frente ás exigências atuais. Suscitamos como problemática desse estudo investigar como as perspectivas da contextualização e interdisciplinaridade foram incorporadas ao Projeto Político Pedagógico dos Cursos de Licenciatura em Química de algumas universidades. Nossos objetivos nessa pesquisa foram: analisar o conteúdo dos documentos institucionais que orientam o currículo dos cursos de química quanto à presença da contextualização e interdisciplinaridade e investigar que concepção de contextualização e interdisciplinaridade aparece nos Projetos Políticos Pedagógicos de alguns cursos de química. Escolheu-se como metodologia a pesquisa bibliográfica e documental, por ser o melhor caminho para atingirmos os objetivos. Consideramos que a interdisciplinaridade e a contextualização presentes na reforma do Ensino Médio Brasileiro não atingiram com segurança conceitual e epistemológica a formação de professores de química.
\end{abstract}

PALAVRAS-CHAVE: Interdisciplinaridade. Contextualização. Formação de Professores. 


\section{Tematizando a Questão}

A educação em um mundo globalizado precisa romper com a fragmentação e a linearidade do conhecimento, tornando-o aplicável à vida e aos problemas sociais. Para Sacristán (2008), a educação pode ser um instrumento para dar consciência dessa realidade e colaborar para desvendá-la.

Neste contexto, o ensino e aprendizagem de química têm acontecido ainda de forma mecânica e informativa, mesmo diante das novas tecnologias e de vários recursos didáticos que podem ser usados nesse processo. 0 currículo de formação de professores de química, ainda se mantém acrítico quanto às questões sociais e desconectado da realidade dos licenciandos. (ver, por exemplo, MALDANER, 2006; SANTOS E SCHNETZLER, 2010, RIBEIRO E MESQUITA, 2012). Contrário a isso, é preciso que o cotidiano seja contemplado "nas aulas de química, para que partindo dela seja possível trabalhar os conteúdos químicos de maneira contextualizada, possibilitando ao aluno aprender a fazer diferentes leituras dessa realidade e, assim, ser sujeito de sua aprendizagem" (RIBEIRO E MESQUITA, 2012. p. 169).

Os conteúdos curriculares de química precisam servir para a introdução do aluno no mundo do conhecimento científico e da tecnologia, sendo utilizados para formar senso crítico na luta pelos seus direitos, no cumprimento de seus deveres, na defesa do próximo e do meio ambiente, etc. Nessa visão, a formação docente em química deve romper com a neutralidade, passando a assumir seu papel de formadora de cidadãos aptos a intervirem nessa sociedade em transformação.

A perspectiva da contextualização e da interdisciplinaridade do ensino veio à tona com a reforma do Ensino Médio, logo após a promulgação da Lei de Diretrizes e Bases da Educação Nacional (LDB 9394/96), que apresenta em seu discurso a necessidade da compreensão dos conhecimentos para uso no contexto social, valorizando a experiência extraescolar, como também como meio de romper com a linearidade do conhecimento.

A reforma do Ensino Médio iniciada após a LDB assumiu como pilares do seu processo formativo a interdisciplinaridade e a contextualização. Contextualizar o conhecimento de forma interdisciplinar passou a ser uma questão de ordem no ensino de química para o ensino médio.

Os Parâmetros Curriculares Nacionais para o Ensino de Química assumiram, então, a perspectiva da contextualização e da interdisciplinaridade ao visar um ensino de química pautado na relação do conhecimento científico e o contexto social.

Tendo em vista as diretrizes para a educação brasileira, surgidas com a Lei de Diretrizes e Bases da Educação (LDB 9394/96), os cursos de licenciatura têm passado por reformas, buscando melhorar a formação de professores para a superação da racionalidade técnica, reinante nesses cursos desde sua criação na década de 1930. Para isso, a elaboração do Projeto Político Pedagógico dos cursos de licenciatura como norte para a organização curricular e para a ação docente, passou a ser o ponto inicial das reformas do ensino superior na educação brasileira.

A base do Projeto Político Pedagógico tem sua fundamentação na LDB 9394/96 de 20 de dezembro de 1996, que em seu artigo 12ㅇ diz que "os 
(BRASIL, 1996). Tal proposta deve ter como objetivo principal orientar o currículo de formação dos futuros professores, como também nortear a ação docente dos professores formadores para que, em consonância com o currículo, possa ser eficaz na melhoria da formação docente.

Para que o Projeto Político Pedagógico dos cursos de licenciatura não se torne uma simples adequação à lei, precisa ser elaborado tendo a participação docente como elemento central, por isso a LDB 9394/96 em seu artigo 13 nos diz que "Os docentes incumbir-se-ão de: I - participar da elaboração da proposta pedagógica do estabelecimento de ensino e II - elaborar e cumprir plano de trabalho, segundo a proposta pedagógica do estabelecimento de ensino" (ibid.).

Segundo Veiga (2008, p. 13), o Projeto Político Pedagógico,

É uma ação intencional, com um sentido explícito, com um compromisso definido coletivamente. Por isso, todo projeto pedagógico da escola é, também, um projeto político por estar intimamente articulado ao compromisso sociopolítico com os interesses reais e coletivos da população majoritária. E político no sentido de compromisso com a formação do cidadão para um tipo de sociedade.

A construção de um Projeto Político Pedagógico dever ser uma ação participativa e que congregue representantes de vários segmentos do curso. A participação da comunidade educativa promove amplitude e riqueza de discussões, como também aumenta o senso de responsabilidade em tornar concretas as ações planejadas.

O Projeto Político Pedagógico constitui-se de um documento que necessita estar em constante discussão e reflexão a partir da ação docente desenvolvida, pois contribui com toda a organização do curso, já que orienta as atividades desenvolvidas no processo educativo, tais como: planejamento, metodologia, avaliação e currículo.

Visando superar problemas estruturais e funcionais das licenciaturas, após a LDB 9394/96 foram criadas as Orientações Curriculares Nacionais para os Cursos de Química, além de resoluções e pareceres que determinavam o tempo de duração dos cursos, carga horária, etc.

Os cursos de licenciatura em química não cumprindo adequadamente o seu papel, suscitaram necessidades de mudança. Essas mudanças, no entanto, não poderiam ocorrer só na estrutura curricular, com a inserção de disciplinas, aumento no estágio dos futuros professores ou buscando criar projetos políticos pedagógicos para os cursos de licenciaturas em Química.

Suscitamos como problemática do nosso estudo investigar como a perspectiva da contextualização e da interdisciplinaridade, pilares da reforma do ensino médio, foram incorporadas ao Projeto Político Pedagógico dos Cursos de Licenciatura em Química de algumas universidades brasileiras.

Nossos objetivos nessa pesquisa foram: a) analisar o conteúdo dos documentos institucionais que orientam o currículo dos cursos de química quanto à presença da contextualização e da interdisciplinaridade e b) investigar que concepção de contextualização e interdisciplinaridade aparece nos Projetos Políticos Pedagógicos de alguns cursos de química de universidades brasileiras. 
Trabalhar a formação de professores de química numa perspectiva de contextualização e de interdisciplinaridade vai requer uma nova orientação curricular que leve em consideração aspectos sociais, políticos, econômicos, culturais, éticos e ambientais, focando a formação docente num viés reflexivo e midiatizador do processo de ensino aprendizagem.

\section{Pressupostos Metodológicos}

A pesquisa desenvolvida teve uma abordagem qualitativa, pois é "um processo de reflexão e análise da realidade através da utilização de métodos e técnicas para compreensão detalhada do objeto de estudo em seu contexto histórico e/ou segundo sua estruturação" (OLIVEIRA, 2008, p. 37).

Escolhemos como metodologia as pesquisas bibliográfica e documental, por estas serem o melhor caminho para se chegar ao nosso objetivo proposto. Apesar da semelhança entre pesquisa bibliográfica e pesquisa documental, preferimos tratá-las distintamente, devido à diferença das fontes escritas consultadas durante a pesquisa.

O primeiro passo da pesquisa foi a pesquisa bibliográfica, na qual foram realizadas consultas a livros e artigos científicos. Nessa garimpagem pudemos fundamentar melhor nosso objeto de pesquisa no que diz respeito a conceituar contextualização e interdisciplinaridade e sua inserção na formação de professores, bem como investigar trabalhos e pesquisas que utilizam o tema.

Em um segundo momento, o da parte documental (documentos sem trato científico como leis, pareceres e diretrizes), fomos à busca dos Projetos Políticos Pedagógicos dos cursos de química de algumas universidades brasileiras. As informações documentais foram de grande importância, fornecendo dados que puderam contribuir para a confirmação de informações de outras fontes, além de aprofundar a realidade, pois eles "não são apenas uma fonte de informação contextualizada, mas surgem num determinado contexto e fornecem informações sobre esse mesmo contexto." (LUDKE e ANDRÉ, 2001, p. 39).

Coletamos ao todo seis Projetos Políticos Pedagógicos, sendo um das regiões Norte, Sul, Centro-oeste e Sudeste e dois da região Nordeste.

$\mathrm{Na}$ análise dos dados, segundo Sá-Silva, Almeida e Guindani (2009, p. 11) buscamos:

\footnotetext{
Relacionar a frequência da citação de alguns temas, palavras ou ideias em um texto para medir o peso relativo atribuído a um determinado assunto pelo seu autor. Pressupõe, assim, que um texto contém sentidos e significados, patentes ou ocultos, que podem ser apreendidos por um leitor que interpreta a mensagem contida nele por meio de técnicas sistemáticas apropriadas.
}

Reunimos todo o material coletado e procedemos a uma leitura minuciosa, buscando informações que estivessem em consonância com nosso objeto de estudo. 


\section{Encontrando com o Objeto de Pesquisa.}

A reforma do Ensino Médio teve como pilares a interdisciplinaridade e a contextualização visando superar o ensino fragmentado, linear e descontextualizado da realidade cotidiana do estudante. Tais princípios passaram a nortear a ação docente dos professores do Ensino Médio brasileiro sem, contudo, levar em consideração a necessidade de formação para assumir na sala de aula tais elementos norteadores de uma prática pedagógica inovadora e dinâmica.

Espera-se, então, que na formação inicial dos futuros professores de química, a interdisciplinaridade e a contextualização tenham sido contempladas nos Projetos Políticos Pedagógicos das instituições formadoras, uma vez que estes são norteadores do fazer docente no ensino superior.

Inicialmente fizemos uma pesquisa visando encontrar Projeto Político Pedagógico de cursos de licenciatura em química dos estados das cinco regiões brasileiras. Tal pesquisa realizada pela internet nos sites das universidades nos rendeu dezesseis Projetos Político Pedagógico, de onde optamos por selecionar dois da Região Nordeste, de onde somos oriundos e um de cada uma das outras regiões brasileiras, assim escolhemos os seguintes PPP para serem analisados: Universidade Estadual do Ceará (UECE) e Universidade Federal do Ceará (UFC) da Região Nordeste; Universidade Federal de Mato Grosso (UFMT) da Região CentroOeste; Universidade Federal do Paraná (UFPR) da Região Sul; Universidade Federal de Roraima (UFRR) da Região Norte e por fim o da Universidade Federal de São Carlos (UFSCAR) da Região Sudeste.

Após a seleção dos Projetos Políticos Pedagógicos dos cursos de Licenciatura em Química procedemos a uma primeira leitura detalhada de todo o projeto para, em uma segunda leitura, começarmos uma análise atenciosa na busca da presença e concepção de interdisciplinaridade e contextualização nestes documentos institucionais.

A análise dos dados coletados se deu seguindo a estratégia geral de "basearse em proposições teóricas" (YIN, 2001), uma vez que fizemos uma ampla revisão da literatura com intenção de ampliar nossos pressupostos teóricos.

As evidências foram analisadas seguindo a adequação ao padrão que "compara um padrão fundamentalmente empírico com outro de base prognóstica (ou com várias outras previsões alternativas)" (TROCHIM 1989, apud YIN, 2001, p. 136).

Segundo Gil (2009, p. 94)

A adequação ao padrão envolve a especificação de um padrão teórico, a aquisição de um padrão empírico a demonstração dos vínculos ou das discrepâncias entre os dois. Se os padrões se ajustassem em duas ou mais instâncias dentro de um estudo de caso único ou entre os diversos casos de um estudo de casos múltiplos, então sua validade interna estaria reforçada.

Nesse estudo analítico/descritivo, fizemos várias análises, procurando sempre manter uma relação entre o arcabouço teórico e as evidências coletadas.

Fundamentamos nossa análise documental, no tocante a interdisciplinaridade, em autores como Fazenda, 2001 e 2008; Paviani, 2008 e 
Trindade, 2008. Sobre a necessidade de contextualização do conhecimento trabalhamos com Silva, 2003; Silva e Marcondes, 2010 e Santos, Silva e Silva, 2013.

Nossa análise foi focada em três pontos comuns aos Projetos Político Pedagógico dos cursos selecionados, foram eles: a) Apresentação ou introdução; b) Competências e habilidades e c) Estrutura Curricular.

\section{Interdisciplinaridade nos Documentos Institucionais.}

$\mathrm{Na}$ apresentação dos Projetos Político Pedagógico da UECE e UFC observamse referências à interdisciplinaridade de forma explicita, enquanto que nos outros ela aparece de forma mais sutil.

\footnotetext{
O nosso Projeto Político-Pedagógico, assenta-se sobre conceitos de "matéria" e "interdisciplinaridade", e usa de forma responsável a autonomia acadêmica, flexibilizando os currículos às especificidades institucionais e regionais e permitindo que cada estudante possa fazer escolhas para melhor aproveitar suas habilidades, sanar deficiências e realizar desejos pessoais. (UECE, 2010, p. 9).

As estratégias pedagógicas recaem, diretamente, no planejamento e na construção de um currículo que fortaleça uma sólida formação e que assegure princípios da flexibilização e da interdisciplinaridade. Considera-se, ainda, como marca deste projeto, a implementação de um processo de acompanhamento e avaliação institucional que permitirá uma atualização permanente desta proposta. (UFC, 2005, p. 3).
}

Os documentos institucionais analisados trazem em sua prescrição a perspectiva da interdisciplinaridade sem, contudo, clarificar e orientar como isso se dará na ação docente do professor formador.

Fica clara a presença da interdisciplinaridade nos Projetos Políticos Pedagógicos analisados, no entanto, qual concepção de interdisciplinaridade será assumida no Projeto Político Pedagógico e no desenvolvimento curricular do curso não se mostra evidente.

No que concerne às competências e habilidades a serem desenvolvidas na formação pessoal do licenciando em Química para uma atuação de qualidade em seu exercício da docência, os Projetos Políticos Pedagógicos de quatro das universidades UECE, p. 13; UFMT, p. 24; UFRR, p. 3 e UFSCAR, p. 30, trazem uma mesma exigência:

\footnotetext{
Ter interesse no auto aperfeiçoamento contínuo, curiosidade e capacidade para estudos extracurriculares individuais ou em grupo, espírito investigativo, criatividade e iniciativa na busca de soluções para questões individuais e coletivas relacionadas com o ensino de Química, bem como para acompanhar as rápidas mudanças tecnológicas oferecidas pela interdisciplinaridade, como forma de garantir a qualidade do ensino de Química.
}

Essa competência e habilidade encontra-se presente nas Diretrizes Curriculares Nacionais para os Cursos de Química, tendo sido literalmente copiadas para os Projetos Políticos Pedagógicos analisados, sem uma interpretação crítica.

A formação docente numa perspectiva interdisciplinar requer uma mudança na postura docente e discente ante o conhecimento, como categoria de ação, a 
interdisciplinaridade exige atitude, coerência, contextualização, reflexão, ousadia, cooperação e respeito, princípios estes fundamentais para uma prática interdisciplinar (FAZENDA, 2001).

Uma ação docente dentro desses princípios nos levará a buscar parceria e integração entre as disciplinas, articulando teoria e prática de forma coerente, num movimento de reflexão-ação, promovendo o conhecimento de si mesmo e no desenvolvimento do outro e da realidade.

A interdisciplinaridade transcende a perspectiva de relação entre disciplinas e assume a característica de ação e atitude como nos coloca Fazenda (2001, p. 11) ao dizer que,

Interdisciplinaridade é uma nova atitude diante da questão do conhecimento, de abertura à compreensão de aspectos ocultos do ato de aprender e dos aparentemente expressos, colocando-os em questão. Exige, portanto, na prática uma profunda imersão no trabalho cotidiano.

Formar professores na perspectiva da interdisciplinaridade requer mudança na prática pedagógica dos professores formadores nas universidades, pois o modelo no qual ensinar é transferir conhecimento, não se apresenta interdisciplinar. A interdisciplinaridade pressupõe diálogo e interação, fugindo a uma estrutura linear e hierarquizada, em que o fazer docente constituído de vários saberes não pode ser reduzido somente aos saberes disciplinares (FAZENDA, 2008).

Quanto à estrutura curricular, a questão da interdisciplinaridade aparece com diferentes enfoques.

No Projeto Político Pedagógico da UFRR a interdisciplinaridade aparece como uma exigência dos documentos oficia que nortearam o Projeto Político Pedagógico quando diz que "Segundo as Diretrizes Curriculares Nacionais para os cursos de Química, são conteúdos essenciais ao CLQ (Curso de Licenciatura em Química), devem conter conceitos que integrem entre os conteúdos de química e correlações entre química e áreas afins, objetivando a interdisciplinaridade" (2011, p. 6).

No Projeto Político Pedagógico da UECE e da UFPR a interdisciplinaridade aparece com o objetivo de superação da fragmentação e linearidade do conhecimento.

Os conteúdos e métodos das oito (08) disciplinas do Eixo Interdisciplinar objetivam superar as fragmentações curriculares, enfatizando a interdisciplinaridade entre o conhecimento científico e as relações sociais e humanísticas. As seguintes disciplinas compõem esse eixo: Monografia I e Monografia II, Mineralogia, História e Filosofia das Ciências, Introdução à Filosofia, Ciência, Tecnologia e Sociedade, Inglês Instrumental, Biofísica e Ecologia e Recursos Naturais. (UECE, 2010, p. 19).

O curso de Licenciatura em Química está estruturado de forma a associar os conhecimentos químicos a outros interdisciplinares (disciplinas temáticas), ampliando a visão do futuro professor, e a outros conhecimentos de caráter mais geral, garantindo uma visão abrangente da Química como ciência, essencial na formação do profissional do ensino. (UFPR, 2008, p. 28 e 29). 
Observa-se, no entanto, uma questão contraditória no prescrito de ambas as citações. A interdisciplinaridade é citada em seu real objetivo no que concerne a ampliar horizontes e formar professores dentro de uma visão holística do conhecimento, no entanto, esse objetivo é atribuído apenas a algumas disciplinas do currículo e não a todo o desenvolvimento curricular.

Nos outros Projetos Políticos Pedagógicos a interdisciplinaridade aparece apenas nas ementas de algumas das disciplinas da estrutura curricular, sendo quase sempre nas disciplinas ditas de cunho pedagógico, o que mostra também que a questão da interdisciplinaridade não perpassa pela maioria das disciplinas curriculares dos cursos.

A interdisciplinaridade na formação de professores de química surge como uma forma de quebrar a formação fragmentada e linear, que não dá conta de formar professores para uma sociedade em transformação, onde o processo educativo precisa ser visto em seus aspectos sociais, culturais, políticos e éticos.

A interdisciplinaridade não tem o objetivo de quebrar a estrutura disciplinar presente na universidade e a especificidade das ciências, seu intuito é o de ampliar horizontes evitando a fragmentação do conhecimento, para assim "possibilitar elos comuns no intercâmbio entre o conhecimento e a realidade" (PAVIANI, 2008, p. 40).

Para Trindade (2008, p. 65),

O caráter interdisciplinar da história da ciência não aniquila o caráter necessariamente disciplinar do conhecimento científico, mas completa-o, estimulando a percepção entre os fenômenos, fundamental para grande parte das tecnologias e desenvolvimento de uma visão articulada do ser humano em seu meio natural, como construtor e transformador desse meio.

A neutralidade das ciências tem promovido na formação docente, professores acríticos e especializados diante do conhecimento (CACHAPUZ ET AL, 2008), no entanto na sociedade atual o que se observa é a necessidade de relacionar o conhecimento científico com outros conhecimentos, promovendo uma amplitude de saberes, que permitam a interferência na realidade social, econômica, política e ecológica com a consequentemente melhoria da sociedade e da qualidade de vida.

\section{Contextualização nos Documentos Institucionais}

A contextualização é fundamental no ensino e aprendizagem, uma vez que motiva, desperta a curiosidade e estimula o interesse dos alunos, partindo da realidade cotidiana dos alunos a contextualização faz com que estes vejam significado no que está sendo estudado.

Santos, Silva e Silva $(2003$, p. 3) nos coloca que,

Apesar do uso de várias metodologias nos dias de hoje, ainda pode ser observado que muitos alunos adquirem o conhecimento de forma isolada, apresentando uma visão restrita do mundo, deste modo, a contextualização de conteúdos é caracterizada como uma ferramenta facilitadora no ensino, uma vez que pode minimizar a fragmentação dos conteúdos, além de contribuir para a formação do aluno como cidadão crítico e pensante. 
O professor precisa estar apto a despertar o senso crítico, através de uma reflexão constante da realidade social, pois a "prática educacional é antes de tudo uma prática social e, portanto é dotada de intencionalidades, visões de mundo e atitudes que devem ser discutidas no sentido de uma educação em estreita relação com a sociedade e os problemas a ela correlatos". (MANFREDO, 2004, p. 2471)

A contextualização não aparece na introdução ou apresentação de nenhum dos Projetos Políticos Pedagógicos analisados.

Presente apenas nas competências e habilidades do Projeto Político Pedagógico do curso de Licenciatura em Química da UFRR, a contextualização aparece na formação pessoal do licenciado dizendo que esta deve "estabelecer relações entre os conhecimentos da química e a realidade local e regional, de modo a produzir um conhecimento contextualizado e aplicado ao cotidiano dos alunos (2011, p. 3)".

A contextualização surge como uma estratégia que permitirá uma formação mais completa dos alunos no que diz respeito à motivação e promoção de uma aprendizagem significativa, uma vez que exerce uma formação crítica e conectada com a realidade social.

Conforme Santos, Silva e Silva (2012, p. 2), "contextualizar é construir significados, incorporando valores que explicitem o cotidiano, com uma abordagem social e cultural, que facilitem o processo da descoberta. É levar o aluno a entender a importância do conhecimento e aplicá-lo na compreensão dos fatos que o cercam".

A função da contextualização é desenvolver valores e atitudes para formar cidadãos aptos ao exercício da cidadania consciente em seu meio social, pois "quando o homem compreende sua realidade, pode levantar hipóteses sobre o desafio dessa realidade e procurar soluções. Assim, pode transformá-la e com seu trabalho pode criar um mundo próprio: seu eu e suas circunstâncias" (FREIRE, 1997, p. 30).

$\mathrm{Na}$ estrutura curricular de todos os Projetos Políticos Pedagógicos analisados, a contextualização aparece na ementa de algumas das disciplinas, sendo observada a mesma questão já abordada no que tange à interdisciplinaridade, ou seja, a questão da contextualização fica relegada às disciplinas de cunho pedagógico, não se corporificando em toda estrutura curricular dos cursos de química.

O ensino de química precisa assumir de forma mais crítica, a formação de cidadãos conscientes de seu papel social e político, facilitando o acesso às novas tecnologias e descobertas científicas, buscando através de uma contextualização, dar ao conteúdo estudado uma aplicabilidade para a vida.

\section{Considerações Finais}

As Reformas Educacionais juntamente com os documentos oficiais surgidos após a LDB 9394/96, trazem no decorrer do seu texto referências à interdisciplinaridade e a contextualização, sem, contudo, clarificar seus conceitos, quais seus princípios, pressupostos teóricos e características. 
A interdisciplinaridade aparece como questão primordial nos Projeto Político Pedagógico analisados tendo como objetivo a melhoria da formação docente, tendo como perspectivas a contextualização e o trabalho coletivo, objetivando não o rompimento com a disciplinaridade, mas sim a promoção de um elo entre as disciplinas, ampliando os horizontes do conhecimento.

A fragmentação e linearidade do conhecimento é um dos pontos a ser superado com a perspectiva de interdisciplinaridade. O conhecimento precisa ser visto em seu todo e não somente em partes.

Espera-se que a interdisciplinaridade possa surgir como uma nova resposta; uma nova pedagogia que privilegie o diálogo estimulando práticas cooperativas, que venham a superar o limite entre as disciplinas e entre os professores com o mesmo objetivo educacional.

Para assumir uma prática interdisciplinar na formação de professores de Química, faz-se necessária uma mudança de postura docente e discente, pois uma prática interdisciplinar requer trabalho coletivo, contextualização do conhecimento, respeito a aprendizagem e desenvolvimento discente, princípios de interdisciplinaridade.

Teoria e prática precisam se articular num movimento de ação-reflexão-ação, caso contrário, estaremos cada vez mais aumentando o abismo entre o prescrito e o vivido na formação de professores de Química.

A concepção de interdisciplinaridade vista nas reformas educacionais e nos documentos oficiais que tratam da formação de professores em geral e de química é a que tem como objetivo superar a visão fragmentada e linear do conhecimento, ampliando o alcance de formação dos alunos e professores.

A contextualização não aparece nos Projetos Políticos Pedagógicos com a mesma relevância da interdisciplinaridade, mas apresenta os mesmos pontos de reflexão, não clarificação dos princípios e características, além de apresentar conceitualmente a concepção mais elementar da contextualização que é o conhecimento associado com o cotidiano.

A interdisciplinaridade e a contextualização presentes nas reformas do Ensino Médio Brasileiro ainda não atingiram com segurança conceitual e epistemológica a formação de professores de química, o que se pressupõe já deveria ter acontecido uma vez que é de responsabilidade das Universidades formarem professores para o exercício da docência no Ensino Médio. 


\title{
Interdisciplinarity and background in political educational projects initial training courses of chemistry teacher
}

\begin{abstract}
Contextualize knowledge in an interdisciplinary way that has become a point of order in teaching chemistry to high school, a requirement to be contemplated in teacher education for ace current requirements. We have raised as problematic this study to investigate the prospects of contextualization and interdisciplinarity that were incorporated into the Educational Policy Project of Degree Courses in Chemistry in some universities. Our objectives in this study were to analyze the contents of institutional documents that guide the curriculum of chemistry courses for the presence of contextualization and interdisciplinarity, and investigate that design context and interdisciplinary appears in the Pedagogical Political Project in some chemistry courses. A methodology was chosen as the bibliographical and documentary research, to be the best way to achieve the goals. We believe that interdisciplinarity and contextualization present in the reform of the Middle School did not meet with Brazilian conceptual and epistemological security training chemistry teachers.
\end{abstract}

KEYWORDS: Interdisciplinarity. Contextualization. Teacher Training. 


\section{REFERÊNCIAS}

BRASIL. Ministério da Educação. Lei de Diretrizes e Bases da Educação Nacional número 9394. Brasília, DF: MEC, 1996.

. Ministério da Educação. Diretrizes Curriculares Nacionais para os Cursos de Química. Brasília, DF: CNE, 2001.

CEARÁ, Universidade Federal do. Projeto Pedagógico da Licenciatura em Química. Fortaleza, CE: UFC, 2005.

CEARÁ, Universidade Estadual do. Projeto Político Pedagógico da Licenciatura em Química. Fortaleza, CE: UECE, 2010.

FAZENDA, Ivani Catarina Arantes (Org.). Dicionário em Construção: interdisciplinaridade. São Paulo: Cortez. 2001.

(Org.). O que é interdisciplinaridade? São Paulo: Cortez. 2008.

FREIRE, Paulo. Educação e Mudança. São Paulo: Paz e terra, 1997.

GIL, Antonio Carlos. Estudo de caso. São Paulo: Atlas, 2009.

LUDKE, Menga; ANDRÉ, Marli. A. Pesquisa em Educação: Abordagens Qualitativas. São Paulo: EPU, 2001.

MALDANER, Otávio Aloísio. A Formação Inicial e Continuada de Professores de Química. Ijuí, RS: Unijuí, 2006.

MANFREDO, Elizabeth Cardoso Gerhardt. A Formação do Professor de Ciências: Elementos Curriculares e Perspectivas em Tempos de Transição. In: Encontro Nacional de Didática e Prática de Ensino, 12, 2004. Curitiba-PR: 2004, p. 24662476, CD ROOM.

MATO GROSSO, Universidade Federal do. Projeto Político Pedagógico da Licenciatura em Química. Cuiabá, MT: UFMT, 2006. 
OLIVEIRA, Maria Marly de. Como Fazer Pesquisa Qualitativa. Petrópolis, RJ: Vozes, 2008.

PARANÁ, Universidade Federal do. Projeto Político Pedagógico da Licenciatura em Química. Curitiba, PR: UFPR, 2008.

PAVIANI, Jayme. Interdisciplinaridade: conceitos e distinções. Caxias do Sul, RS: Educs, 2008.

RIBEIRO, Walber Henrique Ferreira e MESQUITA, Joyce Melo. Um Olhar Reflexivo sobre a Realidade das Aulas de Química em uma Escola Pública Cearense. Revista Essentia. Vol. 13, n², Dez 2011/maio 2012, p. 165-183, 2012.

RORAIMA, Universidade Federal de. Projeto Político Pedagógico da Licenciatura em Química. Boa Vista, RR: UFRR, 2011.

SANTOS, Éverton da Paz; SILVA, Bruna Cristina de França e; SILVA, Givanildo Batista da. A Contextualização como Ferramenta Didática no Ensino de Química. In: VI Colóquio Internacional Educação e Contemporaneidade. São Cristóvão: 2012. Disponível em: < http://www.educonufs.com.br/cdvicoloquio/eixo_06/PDF/39.pdf>Acesso em: 25 de Maio 2013.

SACRISTÁN, J. Gimeno. O currículo: uma reflexão sobre a prática. 3. ed. Porto Alegre: Artmed, 2008.

SANTOS, Wildson Luiz Pereira dos. SCHNETZLER, Roseli Pacheco. Educação em Química: compromisso com a Cidadania. Ijuí-RS: Editora Unijuí, 2010.

SÁ-SILVA, Jackson Ronie; ALMEIDA, Cristóvão Domingos de \& GUINDANI, Joel Felipe. Pesquisa documental: pistas teóricas e metodológicas. Revista Brasileira de História \& Ciências Sociais. Ano 1, no․ 1, Julho/2009, p. 01-14, 2009.

Disponível em:

<http://www.rbhcs.com/index_arquivos/Artigo.Pesquisa\%20documental.pdf> Acesso em: 02 Jan. 2011.

SILVA, Rejane Maria Ghisolfi da. Contextualizando Aprendizagens em Química na Formação Escolar. Revista Química Nova na Escola. Porto Alegre, n. 18, Novembro, p. 26-30, 2003. Disponível em: < http://qnesc.sbq.org.br/online/qnesc18/A06.PDF> Acesso em: 10 Fev. 2016. 
Materiais Didáticos. Revista Ensaio. Belo Horizonte, V.12, n.01, Jan-Abr, p.101118, 2010. Disponível em: <

http://www.portal.fae.ufmg.br/seer/index.php/ensaio/article/viewFile/262/335> Acesso em: 28 Jan. 2016.

SÃO CARLOS, Universidade Federal de. Projeto Pedagógico da Licenciatura em Química. São Carlos, SP: UFSCAR, 2004.

TRINDADE, Diamantino Fernandes. Interdisciplinaridade: um novo olhar sobre as ciências. In FAZENDA, Ivani Catarina Arantes (Org.). O que é interdisciplinaridade? São Paulo: Cortez. 2008.

VEIGA, Ilma Passos Alencastro. Projeto Político Pedagógico da Escola: uma Construção Coletiva. In VEIGA, Ilma Passos Alencastro (Org.). Projeto Político Pedagógico da Escola: uma Construção Possível. Campinas, SP: Papirus. 2008.

YIN, Robert K. Estudo de Caso: Planejamento e Método. Porto Alegre: Bookman, 2001.

Recebido: 02 jun. 2015

Aprovado: $17 \mathrm{fev} .2016$

DOI: http://dx.doi.org/10.3895/rbect.v9n2.3000

Como citar: MOURA, F. M. T. D.; CARNEIRO, C. C. B. S. Interdisciplinaridade e contextualização nos projetos políticos pedagógicos em cursos de formação inicial de professores de química. Revista Brasileira de Ensino de Ciência e Tecnologia, v. 9, n. 2, 2016. Disponível em:

$<$ https://periodicos.utfpr.edu.br/rbect/article/view/3000>. Acesso em: xxx.

\section{Correspondência:}

Francisco Marcôncio Targino de Moura

Rua Frederico Severo № 231 Ap. 204, Messejana, 60.841-585, Fortaleza, Ceará.

Claudia Christina Bravo e Sá Carneiro

Av. Antonio Justa no 2980 Bloco B Ap. 101, Meireles, 60.165-090, Fortaleza, Ceará

Direito autoral: Este artigo está licenciado sob os termos da Licença Creative Commons-Atribuição 4.0 Internacional. 